\title{
Application of particle swarm optimization for gravity inversion of 2.5-D sedimentary basins using variable density contrast
}

\author{
Kunal Kishore Singh ${ }^{1,2}$ and Upendra Kumar Singh ${ }^{1}$ \\ ${ }^{1}$ Department of Applied Geophysics, IIT(ISM), Dhanbad 826004, India \\ ${ }^{2}$ Geological Survey of India, Lucknow-226024, India \\ Correspondence to: Upendra Kumar (upendra.ism@gmail.com)
}

Received: 23 March 2016 - Discussion started: 25 August 2016

Revised: 1 March 2017 - Accepted: 11 March 2017 - Published: 10 April 2017

\begin{abstract}
Particle swarm optimization (PSO) is a global optimization technique that works similarly to swarms of birds searching for food. A MATLAB code in the PSO algorithm has been developed to estimate the depth to the bottom of a 2.5-D sedimentary basin and coefficients of regional background from observed gravity anomalies. The density contrast within the source is assumed to vary parabolically with depth. Initially, the PSO algorithm is applied on synthetic data with and without some Gaussian noise, and its validity is tested by calculating the depth of the Gediz Graben, western Anatolia, and the Godavari sub-basin, India. The Gediz Graben consists of Neogen sediments, and the metamorphic complex forms the basement of the graben. A thick uninterrupted sequence of Permian-Triassic and partly Jurassic and Cretaceous sediments forms the Godavari sub-basin. The PSO results are better correlated with results obtained by the Marquardt method and borehole information.
\end{abstract}

\section{Introduction}

The gravity method is a natural source method which helps in locating masses of greater or lesser density than the surrounding formations. It is used as a reconnaissance survey in hydrocarbon exploration. Sedimentary basins, which are characterized by negative gravity anomalies, are the location of almost all of the world's hydrocarbon reserves. Interpretation of gravity data is a mathematical process of trying to optimize the parameters of the initial model in order to get a good match to the observed data. Interpretation of gravity data is always associated with the ambiguity problem. Ambiguity in gravity anomalies can be over- come by assigning a mathematical geometry to the anomalycausing body with a known density contrast (Rama Rao and Murthy, 1978). Bott (1960) used stacked prism model to describe the cross-section of a sedimentary basin, whereas Talwani (1959) used the polygonal model to describe source geometry. The parabolic density function is used to remove the complications associated with exponential (Cordell, 1973), cubic (Garcia-Abdeslem, 2005) and quadratic (GallardoDelgado et al., 2003) density functions. The Marquardt inversion through residual gravity anomalies delineates the structure of a sedimentary basin by estimating regional background (Chakravarthi and Sundararajan, 2007; Marquardt, 1963). Several authors have developed 2-D/2.5-D local optimization techniques over the 2-D/2.5-D sedimentary basin (Annecchione et al., 2001; Barbosa et al., 1999; Bhattacharya and Navolio, 1975; Gadirov et. al, 2016; Litinsky, 1989; Morgan and Grant, 1963; Murthy et al., 1988; Murthyan and Rao, 1989; Rao, 1994; Won and Bavis, 1987) to interpret gravity anomalies with constant density function. In many publications over 3-D gravity field computation with an approximation of geological bodies by 3-D polygonal horizontal prism has been applied (Eppelbaum and Khesin, 2004; Khesin et al. 1996). Rao (1990) used a quadratic density function, which is comparatively reliable, to analyse gravity anomalies over basins having a limited thickness, whereas Chakravarthi and Rao (1993) carried out modelling and inversion of gravity anomalies with a parabolic density function.

Particle swarm optimization (PSO) is a robust stochastic optimization technique based on the movement and intelligence of swarms, which was developed by Kennedy and Eberhart (1995). PSO applies the concept of social optimization in problem solving in various fields. In this paper, a 


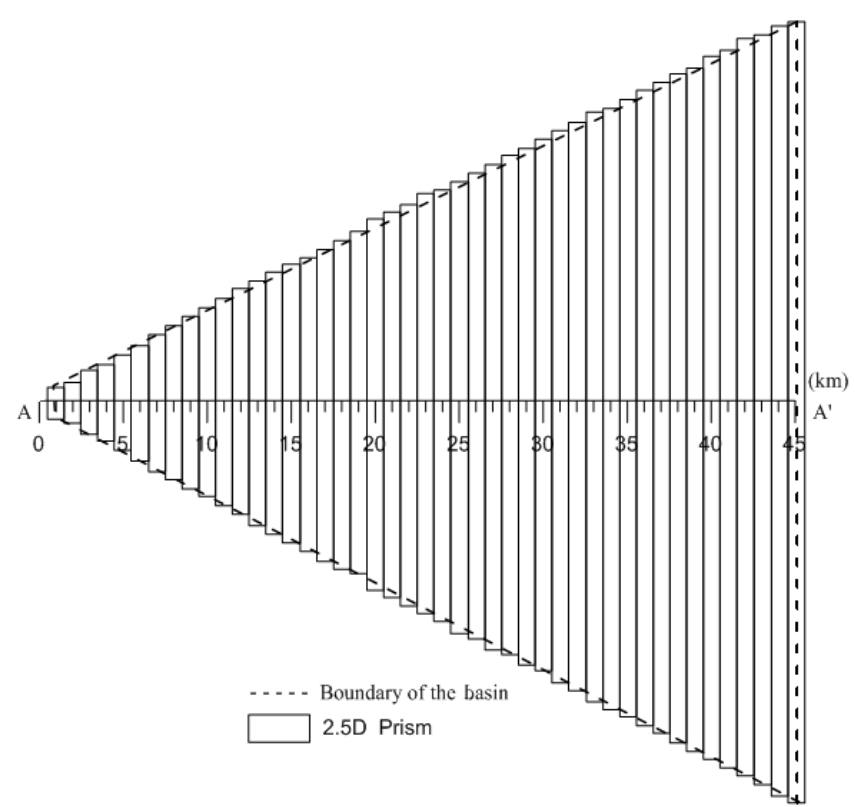

Figure 1. The 2.5-D sedimentary basin and its approximation by juxtaposing prisms.

MATLAB code based on PSO is developed to interpret the gravity anomalies of 2.5-D sedimentary basins, where the density varies parabolically with depth. PSO-analysed results are consistent with and more accurate than other techniques and also agree significantly well with borehole information.

\section{Theory}

In Bott's approach, a sedimentary basin is approximated by a series of vertical prisms. The gravity anomaly $g_{b}$ at any point on the profile $A A^{\prime}$ as shown in Fig. 1.

$g_{\mathrm{b}}=\sum_{j=2}^{N-1} g_{j}\left(x_{l}, 0\right)+C x+D$

The gravity effect of $l$ th prism is given as

$g\left(x_{l}, 0\right)=\int_{z=z_{1} y=-a}^{z_{2}} \int_{x=-c}^{a} \int_{x}^{c} \frac{G \Delta \rho(z) z \mathrm{~d} x \mathrm{~d} y \mathrm{~d} z}{\left[\left(x-x_{1}\right)^{2}+y^{2}+z^{2}\right]^{3 / 2}}$.

The parabolic density function at any depth $w$ is given by

$\Delta \rho(w)=\frac{\Delta \rho_{0}^{3}}{\left(\Delta \rho_{0}-\alpha w\right)^{2}}$.
Finally, after integration of Chakravarthi and Sundararajan (2006), Eq. (2) becomes

$g\left(x_{l}, 0\right)=-2 G \Delta \rho_{0}^{3}$

$\left.\left\{\begin{array}{l}\frac{\alpha x_{1} L}{p_{4}}\left(\frac{1}{p_{2}}+\frac{1}{p_{3}}\right) \ln \frac{p_{5}}{p_{6}}+\frac{L}{2 p_{2}} \ln \frac{\left(K+x_{1}\right)}{\left(K-x_{1}\right)}+\frac{x_{1}}{2 p_{3}} \ln \frac{(K+L)}{(K-L)}+ \\ \frac{\Delta \rho_{0}}{\alpha}\left[\frac{1}{p_{2}} \tan ^{-1}\left(\frac{K L}{z x_{1}}\right)+\frac{1}{p_{3}} \tan ^{-1}\left(\frac{x_{1} L}{z L}\right)\right]-\frac{1}{\alpha p_{5}} \tan ^{-1}\left(\frac{L x_{1}}{z L}\right)\end{array}\right\rangle_{x_{1}-c}^{x_{1}+c}\right\}_{z_{1}}^{z_{2}}$,

where

$$
\begin{aligned}
& K=\left(x_{1}^{2}+L^{2}+z^{2}\right), \\
& \mathrm{p}_{1}=x_{1}^{2}+L^{2}, \\
& \mathrm{p}_{2}=L^{2} \alpha^{2}+\Delta \rho_{0}^{2}, \\
& \mathrm{p}_{3}=x_{1}^{2}+\Delta \rho_{0}^{2}, \\
& \mathrm{p}_{4}=\sqrt{\left(p_{1} \alpha^{2}+\Delta \rho_{0}^{2}\right)}, \\
& \mathrm{p}_{5}=\Delta \rho_{0}^{2}-\alpha z, \\
& p_{6}=-2\left(\alpha K p_{4}+p_{1} \alpha^{2}+\Delta \rho_{0} \alpha z\right) .
\end{aligned}
$$

Here, $N$ is the number of observations, $G$ is the universal gravitational constant, $C$ and $D$ are coefficients of regional background, $c$ is half width of the prism, $z_{1}$ and $z_{2}$ are depths to the top and bottom of the basin, $2 L$ is strike length of the prism, a is the offset of the profile from the centre of the prism and $\Delta \rho_{0}$ and $\alpha$ are constants of the parabolic density function at depth $z$.

Since the profile $A A^{\prime}$ does not pass through the centres of each prism, Eq. (4) has to be calculated twice by putting $L-a$ and $L+a$ for $L$ and taking the average. The initial depths of the basin calculated using observed anomaly $g_{0}$ are given as

$d_{i}=\frac{g_{0}\left(x_{i}\right) \Delta \rho}{41.89 \Delta \rho_{0}^{2}+\alpha g_{0}\left(x_{i}\right)}, i=2,3,4, \ldots \mathrm{N}-1$.

The profile $A A^{\prime}$ entirely covers the lateral dimensions of the sedimentary basin; therefore the depth of the basin on either side of the profile become zero. So, $d_{1}=0=d_{N}$

\subsection{Particle swarm optimization}

PSO uses a number of particles (solutions) that constitute a swarm moving around in the search space looking for the best solution. Each particle adjusts its "flying" according to its own flying experience as well as the flying experience of other particles. Each particle keeps track of its coordinates in the solution space which is associated with the best solution (fitness) that has been achieved so far by that particle. This value is called personal best, $P$ best. Another best value that is tracked by PSO is the best value obtained so far by any particle in the neighborhood of that particle. This value is called global best, $G$ best. The basic idea of PSO lies in accelerating each particle towards its $P$ best and the $G$ best locations with a random weighted acceleration at each time step (Mohapatra 
and Das, 2013).

$$
\begin{aligned}
& V_{t}^{k}=w V_{t}^{k-1}+c_{1} \cdot \operatorname{rand}_{1} \cdot\left(P \text { best }_{t}-X_{t}^{k}\right) \\
& \quad+c_{2} \cdot \operatorname{rand}_{2} \cdot\left(G \text { best }-X_{t}^{k}\right), \\
& \quad X_{t}^{k}=X_{t}^{k-1}+V_{t}^{k},
\end{aligned}
$$

where $k$ is the number of iterations; $t$ is the particle number; $V_{t}^{k}$ is the velocity of the $t$ th particle at $k$ iterations; $X_{t}^{k}$ is the position of $t$ th particle at $k$ iterations; $P$ best $_{t}$ is the best position of individual $t$ th particle (local best position); $G$ best is the best position of all particles (global best position); rand $_{1}$ and rand $_{2}$ are the independent uniformly random numbers in the range $[0,1] ; c_{1}$ and $c_{2}$ are the positive learning factor which controls the maximum step length; and $w$ is the inertial weight factor that controls the speed of the particles. Equation (7) gives the updated velocity based on the current velocity, current position, local, best position and global best position. This process is repeated until the desired result is obtained. The schematic diagram/flow chart of the PSO algorithm is shown in Fig. 2.

\subsection{Examples}

The MATLAB code based on PSO is applied to a synthetic model of a sedimentary basin and real field data sets from Gediz Graben, western Anatolia, and the Godavari sub-basin, India.

\subsection{Synthetic Example}

We have used a synthetic gravity anomaly of $45 \times 10^{3} \mathrm{~m}$ length at a $1.0 \times 10^{3} \mathrm{~m}$ station interval. In Bott's algorithm, the prism will be of equal width, $1.0 \times 10^{3} \mathrm{~m}$, but with different strike lengths. Here parabolic density function is used with the constants $\Delta \rho_{0}=-0.65 \times 10^{3} \mathrm{Kg} \mathrm{m}^{-3}$ and $\alpha=$ $0.04 \times 10^{3} \mathrm{Kg} \mathrm{m}^{-3}$ per $1000 \mathrm{~m}$. The profile does not bisect the strike lengths of prism, and so offset distance of the profile from the centre of each prism is mentioned in the code. We have added an interference term, $A x+B$, with $A=-0.007 \mathrm{mgal}$ per $1000 \mathrm{~m}$ and $B=-10 \mathrm{mgal}$ for the regional background. The required result is found at 15 iterations with a root mean square error (RMSR) of $2.9369 e-006$ from the Marquardt algorithm.

We have used the same synthetic gravity anomaly for the PSO algorithm. The Fig. 3 shows the learning process of $P$ best and $G$ best in terms of error and iterations. The best result is found with 57 iterations and 50 models (Fig. 3). So it is seen that after 57 iterations and 50 models, the calculated anomalies match the synthetic anomaly and estimated depths coincide with the actual structure where the RMSE is $2.8383 e-004$. Gaussian noises of 5 and $10 \%$ are added to the synthetic data to perceive the robustness of the PSO algorithm. PSO does not find the true depths, but it gives values close to the true depths. The upper part of Fig. 4 shows

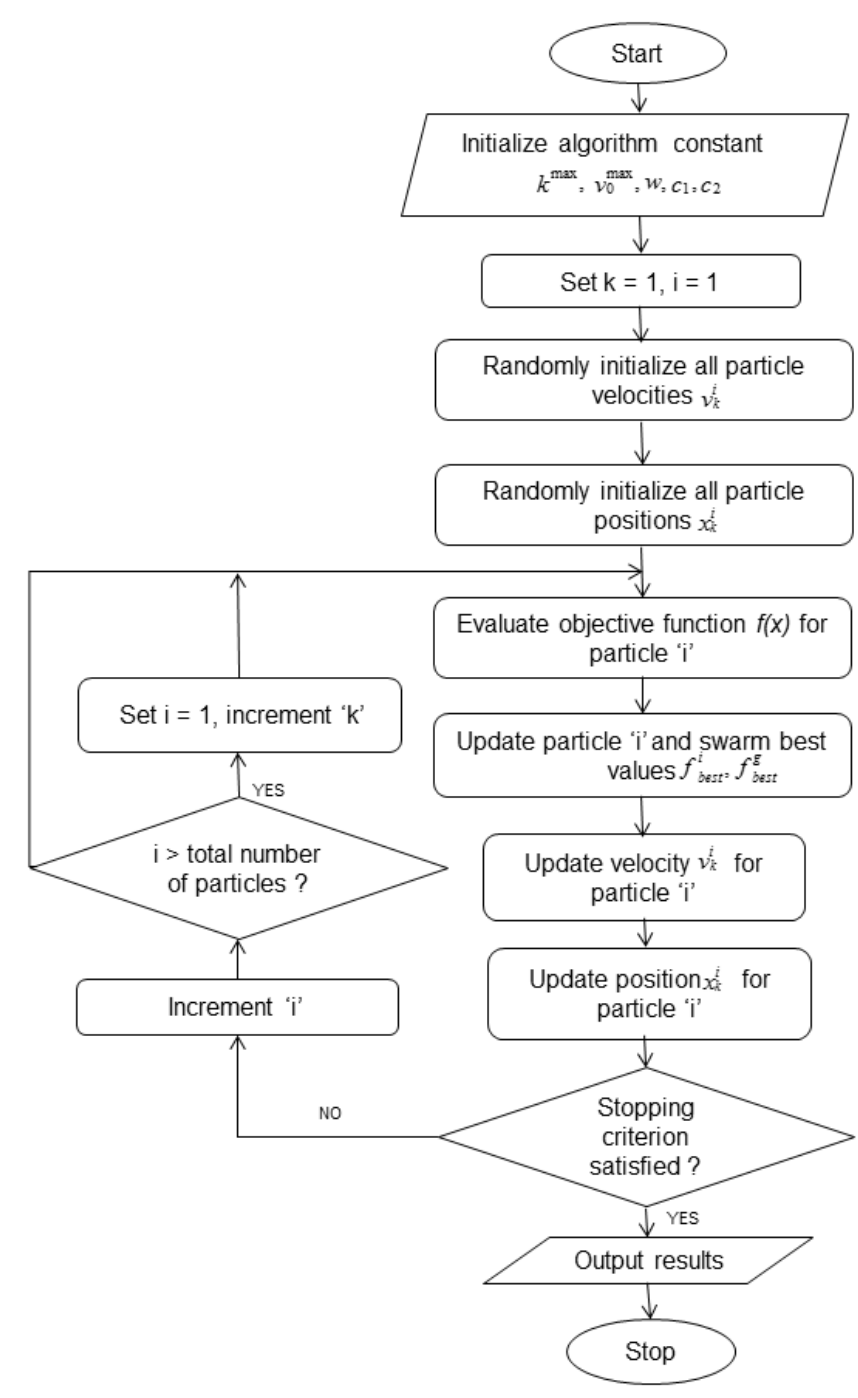

Figure 2. The detail schematic diagram/flow chart of PSO techniques.

the synthetic and PSO-calculated gravity anomalies of a synthetic model of a 2.5-D sedimentary basin, and the lower part shows the inferred depth structure obtained from the PSO and Marquardt algorithm for synthetic data. Figures 5 and 6 show the synthetic data with 5 and $10 \%$ Gaussian noises and calculated gravity anomalies obtained from the PSO algorithm, and inferred depth structure obtained by the PSO and Marquardt algorithm.

\section{Field example}

\subsection{Gediz Graben, western Anatolia}

The first field case study of the interpretation of gravity anomalies has been taken from Gediz Graben, western Anatolia. The PSO technique has been applied using 29 vertical prisms, each with equal width of $2.0 \times 10^{3} \mathrm{~m}$ but with dif- 


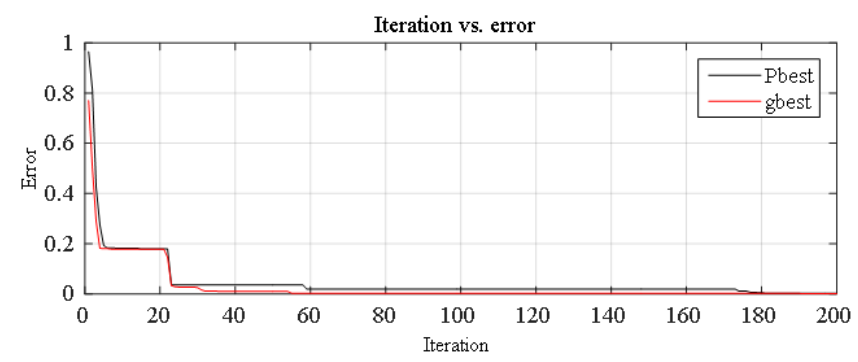

Figure 3. Iteration verses RMSE of $P$ best and $G$ best using the PSO technique through synthetic gravity anomaly.
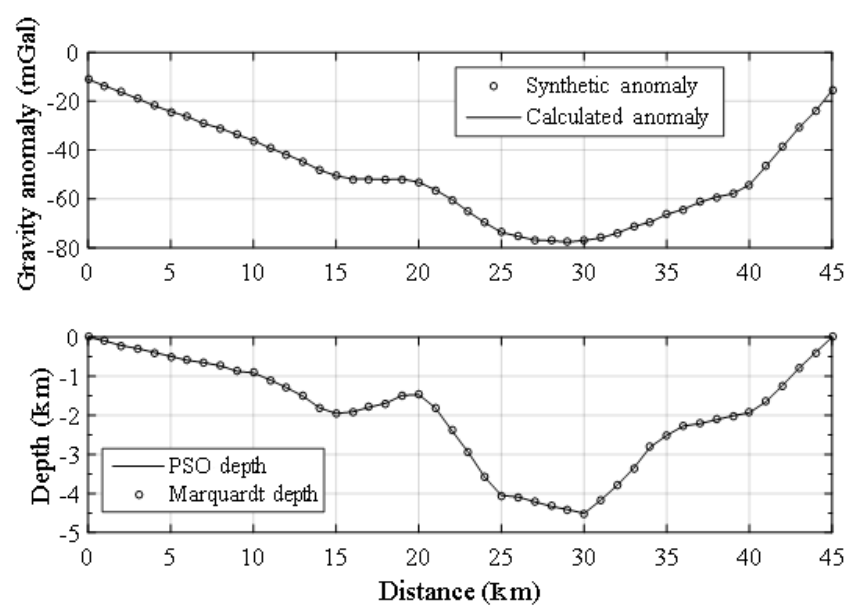

Figure 4. Synthetic and calculated gravity anomalies with parabolic density function due to a synthetic model of a 2.5 -D sedimentary basin, obtained from the PSO algorithm, and inferred depth structure obtained from the PSO and Marquardt algorithm.

ferent strike lengths, whereas Chakravarthi and Sundararajan (2007) used the same prism and interpreted gravity anomaly by the Marquardt algorithm using a parabolic density function whose constants are $\Delta \rho_{0}=-1.407 \times 10^{3}$ and $\alpha=2.26935 \times 10^{3} \mathrm{Kg} \mathrm{m}^{-3}$ per $1000 \mathrm{~m}$.

We have used a similar number of prisms in PSO to improve the results. So with 65 iterations and 50 models, we achieve a good fit between observed and PSO-analysed gravity anomalies with a RMSE of 0.0083 . The maximum thickness of the graben is inferred as $1.87 \times 10^{3} \mathrm{~m}$, which matches well with $1.8 \times 10^{3} \mathrm{~m}$ as estimated by Sari and Salk (2002), as compared to $1.64 \times 10^{3} \mathrm{~m}$ obtained by Chakravarthi and Sundararajan (2007). The upper part of Fig. 7 shows the observed and PSO-calculated gravity anomalies over Gediz Graben, western Anatolia, and the lower part show the inferred depth structure obtained from the PSO and Marquardt algorithm.

\subsection{Godavari sub-basin}

The Godavari sub-basin is one of the major basins of the Pranhita-Godavari valleys (Rao, 1982), whose approximate strike length is $220 \times 10^{3} \mathrm{~m}$. The gravity profile is taken for
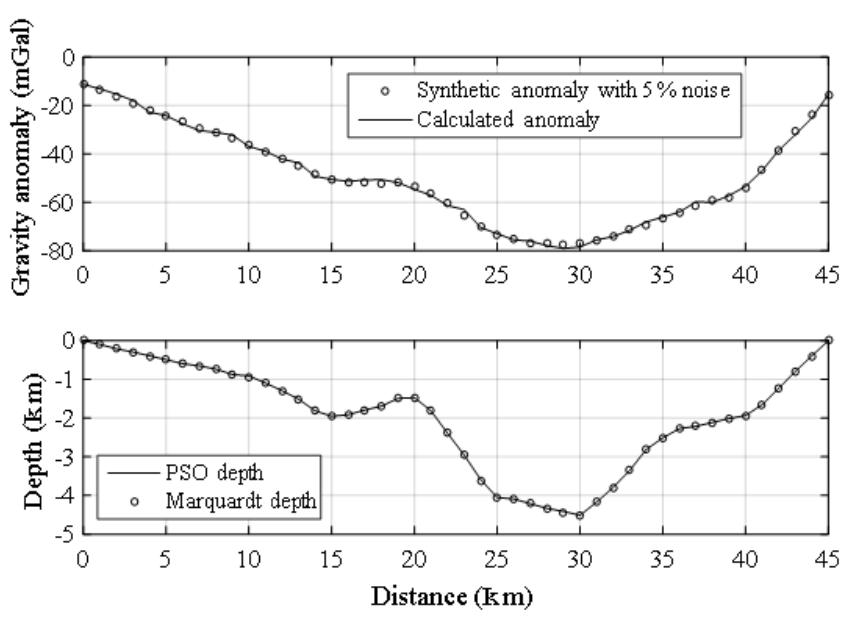

Figure 5. Synthetic data with $5 \%$ Gaussian noise and calculated gravity anomalies obtained from the PSO algorithm, and inferred depth structure obtained from the PSO and Marquardt algorithm.
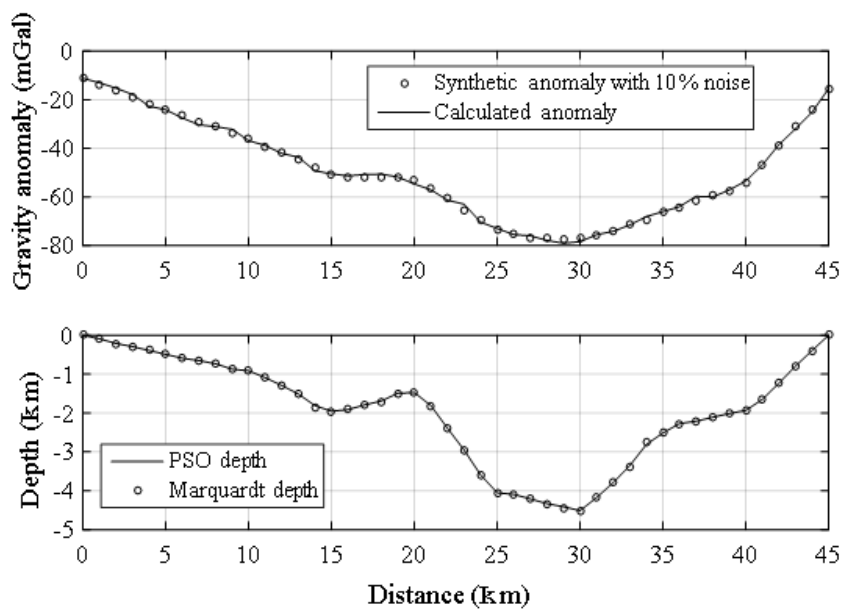

Figure 6. Synthetic data with $10 \%$ Gaussian noise and calculated gravity anomalies obtained from the PSO algorithm, and inferred depth structure obtained from the PSO and Marquardt algorithm.

study from the residual Bouguer gravity anomaly map of the Godavari sub-basin as shown in Fig. 8. We have used 29 vertical prisms, each with equal widths of $2.0 \times 10^{3} \mathrm{~m}$ but with different strike lengths for sedimentary basin modelling. The constants of parabolic density functions used for the Godavari sub-basin are $\Delta \rho_{0}=-0.5 \times 10^{3}$ and $\alpha=0.1518259 \times$ $10^{3} \mathrm{Kg} \mathrm{m}^{-3}$ per $1000 \mathrm{~m}$ (Chakravarthi and Sundararajan, 2004). So with 71 iterations and 45 models, we achieve a good fit between observed and PSO-analysed gravity anomalies. The RMSE is 0.0099 . The maximum depth of the basin, obtained from PSO, is $4.09 \times 10^{3} \mathrm{~m}$, which is quite close to the borehole information (Agarwal, 1995). Chakravarthi and Sundararajan (2005) obtained a maximum depth of $4.0 \times$ $10^{3} \mathrm{~m}$, whereas Ramanamurty and Parthasarathy (1988) suggested $4.5 \times 10^{3} \mathrm{~m}$ as the thickness of the basin. The up- 

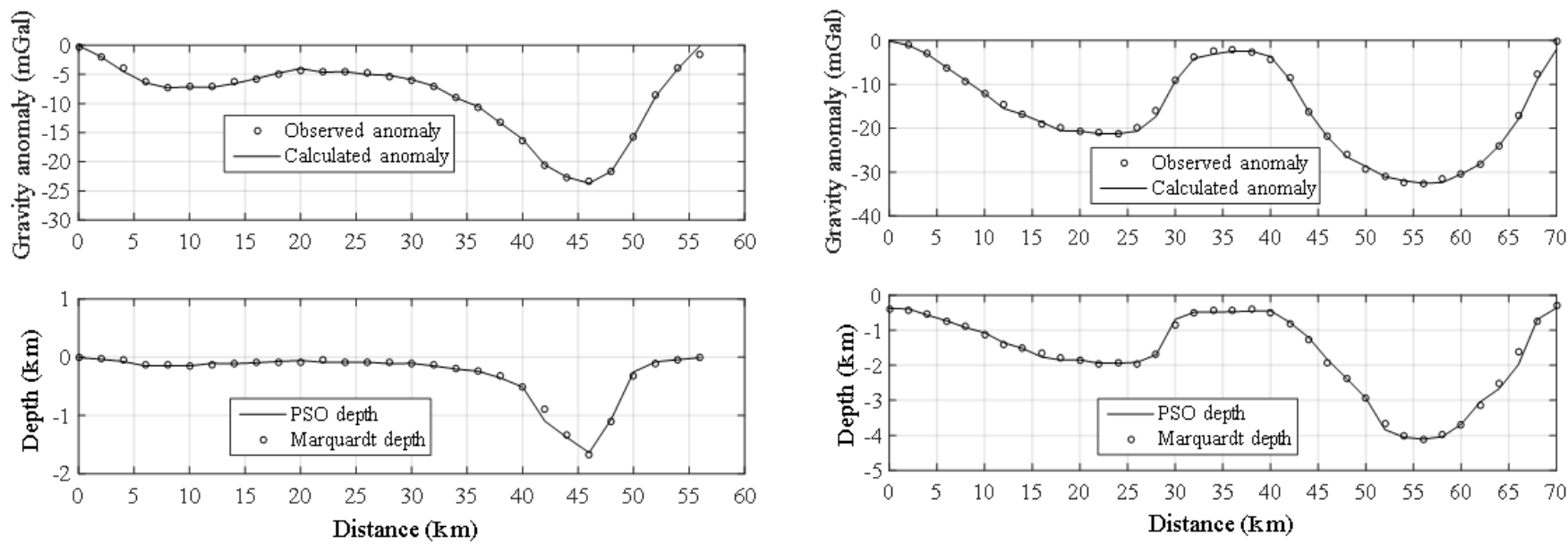

Figure 7. Observed and calculated gravity anomalies with parabolic density function, Gediz Graben, western Anatolia, obtained from the PSO algorithm, and inferred structure obtained from the PSO and Marquardt algorithm.

Figure 9. Observed and calculated residual Bouguer gravity anomalies of parabolic density function of the Godavari sub-basin obtained from the PSO algorithm, and inferred depth structure from the PSO and Marquardt algorithm.

\section{Conclusions}

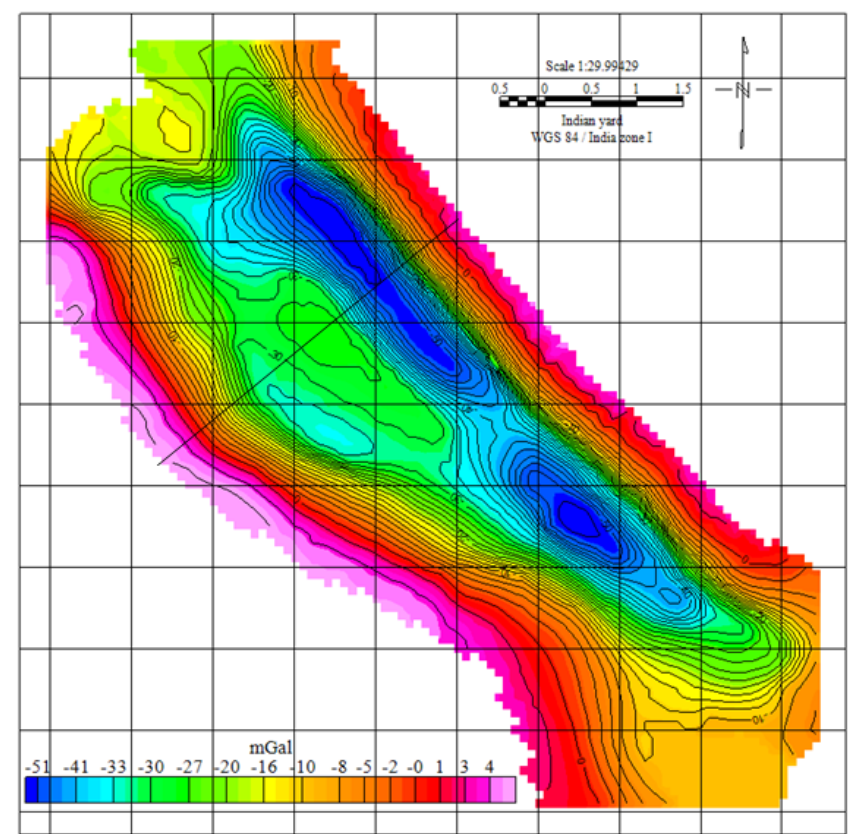

Figure 8. Residual Bouguer gravity anomaly map of the Godavari sub-basin (modified after Chakravarthi and Sundararajan, 2005) and gravity anomaly profile taken for study.

per part of Fig. 9 shows the variation of observed and PSOcalculated gravity anomalies of the Godavari sub-basin, and the lower part shows the inferred structure obtained from the PSO and Marquardt algorithm.
Particle swarm optimization in the MATLAB environment has been developed to estimate the model parameters of a 2.5-D sedimentary basin where the density contrast varies parabolically with depth. We have implemented the PSO algorithm on synthetic data with and without Gaussian noise and two field data sets. An observation has made that PSO is affected by some levels of noise, but estimated depths are close to the true depths. The results obtained from PSO using synthetic and field gravity anomalies are well correlated with borehole samples and provide more geological viability. Despite its long computation time, PSO is very simple to implement and is controlled by only one operator.

Data availability. Our paper presents the applicability and potentiality of PSO in gravity inverse problems. First, PSO is validated on synthetic gravity anomalies with and without noise, and the developed PSO-based algorithm is finally applied over two kinds of field gravity data taken from different geological terrains: (i) residual gravity anomaly over Gradiz Graben, western Anatolia (Sari and Salk, 2002), and (ii) residual gravity anomaly taken from Godavari sub-basin, India (Chakravarthi and Sundararajan, 2004).

Competing interests. The authors declare that they have no conflict of interest.

Acknowledgements. The authors express their sincere thanks to Lev Eppelbaum (associate editor), V. G. Gadirov (referee) and one more anonymous referee for their constructive criticism leading to significant improvement of our manuscript. First author Kunal K. Singh thanks IIT(ISM), Dhanbad (Jharkhand), India, for providing 
the financial support to develop the infrastructre.

Edited by: L. Eppelbaum

Reviewed by: Gadirov and one anonymous referee

\section{References}

Agarwal, B. P.: Hydrocarbon prospects of the Pranhita-Godavari Graben, India, Proceedings of Petrotech 95, 115-121, 1995.

Annecchione, M. A., Chouteau, M., and Keating, P.:Gravity interpretation of bedrock topography: the case of the Oak Ridges Moraine, Southern Ontario, Canada, J. Appl. Geophys., 47, 6381, 2001.

Barbosa, V. C. F., Silva, J. B. C., and Medeiros, W. E.: Stable inversion of gravity anomalies of sedimentary basins with non smooth basement reliefs and arbitrary density contrast variations, Geophysics, 64, 754-764, 1999.

Bhattacharya, B. K. and Navolio, M. E.: Digital convolution for computing gravity and magnetic anomalies due to arbitrary bodies, Geophysics, 40, 981-992, 1975.

Bott, M. H. P.: The use of rapid digital computing methods for direct gravity interpretation of sedimentary basins, Geophys. J. Roy. Astr. Soc., 3, 63-67, 1960.

Chakravarthi, V. and Rao, C. V.: Parabolic density function in sedimentary basin modeling: 18th Annual Convention and Seminar on Exploration Geophysics, Expanded Abstracts, A16, 1993.

Chakravarthi, V. and Sundararajan, N.: Ridge regression algorithm for gravity inversion of fault structures with variable density, Geophysics, 69, 1394-1404, 2004.

Chakravarthi, V. and Sundararajan, N.: Gravity modeling of 2.5D sedimentary basins with density contrast varying with depth, Comput. Geosci., 31, 820-827, 2005.

Chakravarthi, V. and Sundararajan, N.: Gravity anomalies of 2.5D multiple prismatic structures with variable density: a Marquardt inversion, Pure and Applied Geophysics, 163, 229-242, 2006.

Chakravarthi, V. and Sundararajan, N.: INV2P5DSB-A code for gravity inversion of 2.5-D sedimentary basins using depth dependent density, Comput. Geosci., 33, 449-456, 2007.

Cordell, L.: Gravity analysis using an exponential density-depth function - San Jacinto Graben, California, Geophysics, 38, 684690, 1973.

Eppelbaum, L. V. and Khesin, B. E.: Advanced 3-D modelling of gravity field unmasks reserves of a pyrite-polymetallic deposit: A case study from the Greater Caucasus, First Break, 22, 53-56, 2004.

Gadirov, V. G., Gadirov K. V., and Gamidova, A. R.: The deep structure of Yevlakh-Agjabedi depression of Azerbaijan on the gravity-magnetometer investigations, Geodynamics, 1, 133-143, 2016.

Gallardo-Delgado, L. A., Perez-Flores, M. A., and Gomez-Trevino, E.: A versatile algorithm for joint inversion of gravity and magnetic data, Geophysics, 68, 949-959, 2003.

Garcia-Abdeslem, J.: The gravitational attraction of a right rectangular prism with density varying with depth following a cubic polynomial, Geophysics, 70, 39-42, 2005.
Kennedy, J. and Eberhart, R.: Particle Swarm Optimization: International Conference on Neural Network, IEEE, IV, 1942-1948, 1995.

Khesin, B. E., Alexeyev, V. V. and Eppelbaum, L. V.: Interpretation of Geophysical Fields in Complicated Environments, Kluwer Academic Publishers, Springer, Modern Approaches in Geophysics, Boston - Dordrecht - London, 368 p., 1996.

Litinsky, V. A.: Concept of effective density: key to gravity depth determinations for sedimentary basins, Geophysics, 54, 1474$1482,1989$.

Marquardt, D. W.: An algorithm for least squares estimation of nonlinear parameters, Journal Society Indian Applied Mathematics, 11, 431-441, 1963.

Mohapatra, P. and Das, S.: Stock market prediction using bioinspired computing: A survey, Int. J. Eng. Sci., 5, 739-746, 2013.

Morgan, N. A. and Grant, F. S.: High-speed calculation of gravity and magnetic profiles across two-dimensional bodies having an arbitrary cross-section, Geophys. Prospect., 11, 10-15, 1963.

Murthy, I. V. R. and Rao, S. J.: A FORTRAN 77 program for inverting gravity anomalies of two-dimensional basement structures, Comput. Geosci., 15, 1149-1156, 1989.

Murthy, I. V. R., Krishna, P. R., and Rao, S. J.: A generalized computer program for two-dimensional gravity modeling of bodies with a flat top or a flat bottom or undulating over a mean depth, Journal of Association of Exploration Geophysicists, 9, 93-103, 1988.

Rama Rao, B. S. R. and Murthy, I. V. R.: Gravity and Magnetic Methods of Prospecting: Arnold-Heinemann Publishers, New Delhi, India, 390 pp., 1978.

Ramanamurty, B. V. and Parthasarathy, E. V. R.: On the evolution of the Godavari Gondwana Graben, based on LANDSAT Imagery interpretation, J. Geol. Soc. I., 32, 417-425, 1988.

Rao, C. S. R.: Coal resources of Tamilnadu, Andhra Pradesh, Orissa and Maharashtra, Bulletin of the Geological Survey of India, 2, 1-103, 1982.

Rao, C. V., Pramanik, A. G., Kumar, G. V. R. K., and Raju, M. L.: Gravity interpretation of sedimentary basins with hyperbolic density contrast, Geophys. Prospect., 42, 825-839, 1994.

Rao, D. B.: Analysis of gravity anomalies of sedimentary basins by an asymmetrical trapezoidal model with quadratic density function, Geophysics, 55, 226-231, 1990.

Sari, C. and Salk, M.: Analysis of gravity anomalies with hyperbolic density contrast: an application to the gravity data of Western Anatolia, Journal of Balkan Geophysical Society, 5, 87-96, 2002.

Talwani, M., Worzel, J., and Landisman, M.: Rapid gravity computations for two dimensional bodies with application to the Mendocino submarine fracture zone, J. Geophys. Res., 64, 49-59, 1959.

Won, I. J. and Bevis, M.: Computing the gravitational and magnetic anomalies due to a polygon: Algorithms and Fortran subroutines, Geophysics, 52, 232-238, 1987. 